\title{
ARTICLE
}

\section{Material Processuality: Alternative Grounds for Design Research}

Damla Tonuk and Tom Fisher

Tom Fisher is Professor of Art and Design at Nottingham Trent University. He uses materials as a craft practitioner, as well as studying their entanglement with human skills, and systems of value and meaning.

Damla Tonuk is Assistant Professor of Industrial Design at Middle East Technical University. She is interested in the socio-cultural and technological relationships that make up the materiality of everyday lives.

dtonuk@metu.edu.tr

tom.fisher@ntu.ac.uk

ABSTRACT: This article opens discussion on the positivist epistemology underlying the understandings of materials in design research that have been brought along as a result of theory and methods inherited from engineering and psychology. Examining the ambitions of work that seeks to operationalize knowledge created by these methods in the design process, we propose that attending to the processuality of material forms is a more adequate way for design research to capture the multiplicity of materials. We develop this view by exploring the implications of 
the positivistic perspective that underlies recent work on new and smart materials, showing that it limits their theory and methods. This work, therefore, cannot grapple with the liveliness and fluidity of emergent cultural and material forms, and so cannot address the potential and future of emergent materialities. We conclude by arguing for the development of qualitative and ethnographic research methods that are better suited to exploring material processuality.

KEYWORDS: design research, context, epistemology, materials, materiality, ontology

\section{Received Ideas About Relationships Between Designers and Materials}

The World Design Organization (WDO) ${ }^{\mathrm{TM}}$ re-defined industrial design at its 29th General Assembly, 2015:

Industrial Design is a strategic problem-solving process that drives innovation, builds business success, and leads to a better quality of life through innovative products, systems, services, and experiences. [our emphasis]

Hence, designers, whatever their focus, are expected to solve problems, and to foresee and plan a series of actions to mold the world around us into a better place. Current research that aims to support design practice defines these problems both in terms of production processes and in respect of consumers' interaction with the resulting products. Consequently, because design sits between production and consumption, domains typically approached from engineering and natural science on the one hand, and from the humanities and social sciences on the other, design research has adopted methods and approaches from across these disciplines. In this article, we discuss a specific area of design research, which engages with those consumer interactions by focusing on the materials products are made from, and so tries to produce materials-related knowledge to be operationalized in designing. We suggest that some paradoxes arise for this 
research, due to the intellectual traditions on which it draws. This research has often favored a positivistic approach that derives methods from engineering and psychology - that we in caricature refer to as 'scientistic' in the rest of this article. This has resulted in a somewhat restricted focus, as these approaches cannot capture what we term the 'processuality' of material forms - the flows and cycles between production and consumption that influence the ways that materials-in-designs play out in the dynamism of everyday life.

Our criticism is grounded in our own practical engagement with materials as designers and our view is influenced by material culture studies and Science and Technology Studies (STS), which press us to point to some fundamental discrepancies between the reality of materials and that described by scientistic approaches. We are guided in this by the work of social scientists who have pointed out the limitations of such partial approaches for their disciplines, Ingold (2000) for anthropology, Latour (1992) for sociology in general, Miller (2005), and Shove et al. (2007) for material culture studies. ${ }^{1}$ These approaches offer us the idea of the co-constitution and co-evolution of dynamic elements of a material phenomenon that we reflect in our focus on materials in terms of material processuality. We propose that if design ignores processuality it misses reality, and risks producing what Rekret calls 'abstracted knowledge' (2018). Rekret (2018) reminds us that the detachment of manual from mental labor, and the resulting abstraction of knowledge, does not connect with the art of working with the material and the knowledge of the craftsman derived through direct contact with the material; in this respect, it is divorced from the practice of design; i.e., such knowledge does not reflect nor can it grapple with reality. We show that although they use valid techniques, scientistic tools provide only partial insights and cannot encompass what goes on in people's daily interactions with materials outside the lab, and so cannot be operationalized effectively in designing. 
The approach we propose is at odds with the prevailing way of producing knowledge that is intended to be directly applied in design processes through empirically validated 'tools and techniques.' It requires an epistemological shift for design research on materials, away from methods that assume the designer is the generator and the user the receiver of coded information, transmitted through appropriately configured, but essentially inert materials, extending the scope of material research from the lab to real life ethnographies, and from a limited cultural/historical view to phenomenological relationships. Rather than creating frameworks, or tools, or meaning attributes that appear to be actionable, our focus is on understanding a material phenomenon and understanding what is at stake in a given situation, rather than assuming that the salient frames to understand it are semiotic, linguistic, or cognitive. This means that we shift our focus from serving a delimited problem-solving design exercise to delineating the elements that are in play in particular cases of material unfolding. The question that motivates this article is how it is appropriate to know materials for design and the answers we provide (we hope) open up a path for the development of methods that can address the future of material involvement adequately.

To achieve this aim, in the remainder of the article we first examine the origins of scientistic approaches. Then we consider their strengths and weaknesses through an STS lens, addressing the paradoxes they throw up to build our concept of material processuality out of the multiple processes by which materials "materialize" - come to be part of different worlds of design, production and consumption as active agents. We intend to show that knowledge about materials that is grounded in a scientistic perspective isolates designers' efforts to understand materials from the full range of material ontologies - the multiple ways in which materials register. Then we go on to elaborate on the recent work on new materials, because scientistic approaches that do not take material processuality into account have the strongest consequences 
in work that seeks to explore the unfolding of new materials in the near future. We propose that design research should attend to, in effect, all elements of the "processuality" of materials' unfolding. We conclude by indicating certain directions that design research should consider in its approach and development of methods to understand materials.

\section{Origins of Scientistic Approaches to Thinking Materials in/for Design}

Design's attachment to positivistic methods is closely aligned with its definition by its capacity to solve problems for the better. In this view, and from the point of view of production, materials scientists and engineers work on various materials to discover their potential and to make them better suited to everyday circumstances, or to bring about innovation in them. This perspective is strongly influential on design research on materials and its obvious point of connection is to $\underline{\text { specifying materials; }}$ engineers define and specify what materials are from their salient, but restricted point of view, quantifying aspects of our knowledge of them. Many papers in the journal Materials and Design and foundational studies in materials-based research in design emphasize that the point when materials enter the domain of design is the moment when a designer chooses them according to their specifications (Ashby et al. 2004; Van Kesteren 2008; Ramalhete et al. 2010).

However, the moment at which materials cross from the domain of science to the domain of design is not the end of the story; rather, for designers, manufacturers, and users, it is the beginning. As materials are enacted through processes of mass production, consumption, user purchase and use, the problematic consequences of the engineer's way of knowing and specifying materials become acute; while a lab-based approach is at home with the physical qualities of materials, it cannot fully explain the human interactions with materiality, as humans are cultural and emotional as well as physical beings, and always encounter materials through 
social practice. While engineers rarely need to consider these aspects of the materials they work on, designers need a different 'way of knowing' to address their crossover into the consumption sphere.

This realisation is to be found in 'design research' and some researchers have taken steps to work across the border between material science and the material experience, adopting an engineering approach to material experience. For example, Wilkes et al. (2016), try to bridge this gap by working on the terminology used by scientists and designers by giving touch and sound qualities numeric values. But this approach stumbles over the inconsistency in users' responses to materials between situations where the subjects are allowed to see the materials and can associate them with cultural codes, and situations where they cannot see them and so cannot resort to mental categories.

A significant body of work in design seeks to meet this challenge by drawing from psychology to address the shortcomings of an engineering approach. Such 'design and emotion' studies frame responses to designed products through the lens of positive and negative affect (Desmet and Hekkert 2007). Drawing approaches from the psychology tradition, this work uses relatively reductive methods to understand users' interactions with designed objects, with the presumption that if designers know the ways in which the qualities of products are perceived, then they will be able to build these qualities into their designs to address these aspects of consumers' reception of them.

A rich body of design research draws on this design and emotion work to focus on materials as a key element in people's engagement with objects, acknowledging that materials have not only a molecular, but also qualitative, relationships with humans. The Materials Experience Lab at the University of Delft is the prominent example, and has generated

Commented [DT2]: We prefer "resort to" instead of rely upon 
many publications that pay rigorous scientific attention to the particulars of materials as they are apprehended by experimental participants and worked with by students (Camere and Karana, 2017; Karana 2009; Karana et al. 2009, 2010a, 2010b; Rognoli and Karana 2014, among many others). This justly influential body of work takes a critical position on the material selection tools produced by engineering disciplines, arguing they cannot address the multi-faceted relationships through which users appreciate materials. As a result, they have developed tools and techniques, encapsulated as "Materials Driven Design" (MDD), that they argue are more suitable to designers' understanding of materials given their emotive or 'intangible' aspects (Karana et al. 2008, 2010b).

The approaches outlined above do put humans in the picture of course, by virtue of their relationship to psychology, shifting the focus from the designer to a putative user's responses to materials in the spirit of 'user-centred' design. However, they remain scientistic in their approaches. While such approaches arguably have advantages, they have significant downsides in adequately explaining human involvement with materiality. They rather closely follow the tradition of material selection tools that emphasize the process of specifying materials

. Although these approaches appear practical and are predicated on deriving "tools and techniques" that are validated statistically or in a lab context, to be operationalized in the process of design and product development, they cannot engage with the temporal aspect of materials. This character is in stark contrast to Ingold's recommendation in his processual approach that we "not $[\ldots]$ think of the properties of materials as attributes. Rather, [as] histories" (2012:434). The scientistic approach tends to take at face value the cultural dimensions of the elements in play that may elicit positive or negative affect, while ignoring the social practices they constitute (Fisher and Nordli 2009). 
Materials tend to be assessed out of context, often detached from any specific making process and always from actual daily use. These approaches cannot encompass the everyday context and the socio-technical arrangements that design, users, and objects inhabit because they do not engage with the relationships between them or their changes over time. Even the most relational of psychological theories of being in the material world, James Gibson's principle of the affordance (1977), has been criticized for denying the sense in which the material world is not pre-existent and stable (and therefore credibly available for analysis by reductive methods), but is made in the experiencing of it through everyday practices. As Tim Ingold $(2000,168)$ puts it:

Gibson assumed that the world which the perceiver moves around in and explores is relatively fixed and permanent, [...]. From a phenomenological standpoint, by contrast, the world emerges with its properties alongside the emergence of the perceiver in person, against the background of involved activity.

His reference to phenomenology resonates with our proposition of material processuality. We propose this term to emphasize a relational view of the actors relevant to understanding materials, which the dominating positivistic approach disregards. In the next section, we discuss the scientistic approach from the perspective of our concept of processuality.

\section{A Critique of Scientistic Approaches to Materials from a Processual Perspective}

Below, we both discuss aspects of the scientistic approach that do not accord with the processual view we are developing, and also open up and justify this perspective by arguing for multiple environments in which design sits, and the multiple grounds that underlie the actuality of materials by borrowing ideas from STS and material culture perspectives. 
Our first problem with scientistic approaches is the overemphasis of the degree to which materials are taken to be linguistic. While researchers taking a more scientistic approach to materials do distinguish between properties in a functional/tangible context and meanings in an emotional/intangible context, such a semiotic approach can only work in an idealized userproduct relationship because materials take form in social practices. For Wittgenstein, language works through "games," which in order to exist, require that those involved "know the rules" Ehn and Kyng note the importance of this in their early design research for Computer Supported Collaborative Work (1992). Reductive approaches cannot engage with the diverse sets of 'rules,' which might make materials meaningful in a particular social practice. Also, materials (and products) do more than bear meaning; they are actually used, they enable or limit action, they are physically there, and we interact with them not only verbally but also physically in the accomplishment of daily practices. (Miller 2005; Shove et al. 2007). As Latour (1991) explains, a large hotel key-fob is not only heavy but is the bearer of relationships, reminding guests to leave their keys at the reception.

Nor is communication only verbal. If there is anything language-like about materials, it goes beyond words - it encompasses a whole way of being in the world (Reckwitz, 2002). Often, the qualities that human beings recognize in materials are human ones, and as we interact with them to fashion our lives, we humanise them (Fisher 2015). The ways in which materials seem almost to act like humans, or are ascribed human-like properties in this process, resonates with Jane Bennett's ideas. In her political philosophical account of materials, she concentrates on material's active liveliness, "a creative materiality with incipient tendencies and propensities, which are variably enacted depending on the other forces, affects, or bodies with which they come into close contact" (2010: 56). She does not distinguish between the agency of materials 
and humans, she refers to both as "life," arguing that materials are active in shaping the environments in which they are enacted.

Related to this, the second fundamental departure point between scientistic and processual approaches is that scientistic approaches treat the meaning of materials as a property that is intrinsic to them, and so can be defined and operationalized. This assumes meanings can be consistently 'read' out of materials, and that by changing the physical characteristics of products, designers can reliably manipulate materials' meanings, seeking to know meanings or properties of materials as users do, in a way that is useful to designers.

This assumption that materials have stable and intrinsic qualities that can be managed solely by designers is illustrated in Karana et al's $(2015,17)$ description of materials as preformed "characters," ready to be stage managed by designers:

If we regard materials as actors playing a particular role that designers have assigned to them, then we soon begin to understand that some materials are chosen for lead roles in certain applications, while others go unnoticed as essential background actors. [our emphasis]

Such a view has clear implications for the tasks that designers undertake; they should know how users are likely to apprehend the meanings of materials and 'choose' materials accordingly:

Deciding on the role that a material will play in an artifact is one of the creative challenges that designers face. Designers need a good auditioning process, which necessarily entails evaluating potential materials against the dual criteria of people's functional and hedonic needs. (Karana 2015, 18) [our emphasis] 
While the analogy between a designer and a director of a drama does imply that materials might adapt their 'performance' to suit the product(ion), it privileges the designer's power of selection, and implies that the material's 'hedonic and functional' potential are pre-determined. Drawing on lab-based methods of data gathering and statistical analysis from psychology, such a scientistic approach, limited as it is to the designer's powers of evaluation standing in for the consumer's power of selection for purchase, remains an 'apprehension model'from which to develop 'selection tools.'

This focus on apparently intrinsic material meanings is related to the third aspect of scientistic approaches to materials that are problematic from our perspective; that is, the treatment of meanings as fixed. When materials are considered through material culture and STS they are "temporally specific" (Tonuk, 2018). As Fisher (2004) has shown for plastic, a certain class of materials can be understood as hygienic as well as tacky, and such evaluations change as the constellation of materiality and practices changes.

Similarly, Hawkins (2013) has shown how the strength and resistance of the molecular composition of PET has come to be renowned as 'disposable' in the context of ready-to-consume beverages, while at the same time appearing increasingly 'durable' in certain markets such as in recycling and waste management. Tonuk (2016) has shown that the various products that a material is going to be made into, such as bottles or clamshell packaging, and the relevant actors and practices salient to its making are involved in defining materials.

There is a significant body of work that stresses the ways in which the qualities of materials come into being through a process of sociomaterial construction (Drazin 2015; Dant 2008; Ferreira and Scaraboto 2016; Fisher 2004; Gabrys, 2013; Hawkins 2013; Tonuk 2018; Watson 2008). Interested in the multiple elements of

Commented [LM6]: Awkward phrasing - could this sentence be rewritten? Repetition of the word significant. How about, "There is a significant body of work that stresses the ways in which objects' potentially important qualities come into being through a process of socio-material construction." The "play out" seems redundant with the emphasis on the word "process." 
this process, Callon et al., use the term "qualification" to define the "processes through which qualities are attributed, stabilised, objectified and arranged" and further state that:

... all qualification aims to establish a constellation of characteristics, stabilized at least for a while, which are attached to the product and transform it temporarily into a tradable good in the market. (2002:199)

While these authors are concerned with the full range of qualities that define all sorts of products as they enter the market, their terminological preference of "qualities" - as opposed to 'properties' - suits the processual nature of the phenomenon discussed here because they include the semiotic and the sensual unfolding of materials and objects across socio-material processes, and over time.

Another issue we see with a relatively scientistic way of engaging with materials is that it also makes assumptions about designing, where designing is taken to be an isolated, singular, linear, and deterministic event, where designers are paradoxically both passive - receiving meanings that are attributed to materials - and active, in the sense that they can determine what the materials will do. A scientistic approach tends to treat user-material, as well as designer-material relationships in isolation, and the materials themselves are considered as self-evident - when in fact, the multiple realities in which designs are enacted are more complicated and nuanced. As Molotch shows (2005) an electric toaster has been socially and technologically constructed as the result of changing breakfast habits, electrical infrastructures, shopping organization, and so forth. The same goes for materials, as Misa's (1992) STS account of steel shows that American railroads, along with government and material production and supply chains have all contributed to what gets to be defined as steel. 
Bensaude-Vincent and Stengers (1996) explain that materials are already informed with knowledge about the material culture and the practices in which they are enacted. Extending their idea, Barry $(2005,55)$ conceptualizes this as "informed materials" by showing the ways in which pharmaceutical materials are already informed with sought after recipes, existing information technologies, patents, and laboratory equipment. The perspective presented here is not to propose a process of social construction, but to point to the multiple worlds that surround a material reality, and the way the elements of this reality - the different actors making up a material phenomenon - are always on the move. So designers are not working alone with their materials, nor are users with their objects. Rather, they operate in a much broader context of processual relationships.

Having emblematized the limitations of positivistic approaches above - as narrowly linguistic, intrinsic, fixed, and isolated - we will now elaborate on our conceptualization of processuality. Attending to processuality

is useful to designers, in order to move beyond existing approaches to materials, and by extension, to design. Materials are in the making, they are "becoming" (Ingold, 2012), but are also active in these processes themselves: making what they become. This points to a shift in terminology from a restricted focus on materials towards a sense of "materiality," a term elaborated by the contemporary anthropologist and pioneering figure in material culture studies, Daniel Miller. For Miller, "materiality" stands for "the way the specific character of people emerges from their interaction with the material world through practice" $(2007,26)$, as materials (and objects) are never an end in themselves. Here, we use 'materiality'2 to indicate how materials are taken to be at a particular moment and to imply a holistic way of materials 'being' 
with the material world; always contingent and connected to a broader whole rather than as a material component that is distinct from everyday practices.

This definition of 'materiality' emphasizes materials as process; they are constantly in the making, and particularly so in the case of multiple enactments ${ }^{3}$ of a material. As a material is invented and comes to be, and comes to 'mean,' it does so because it corresponds in some way(s) with human practices - both everyday life practices and design practices - which at the same time are bringing it about. Or, more properly in Ingold's (2012) terms perhaps, helping a material to come forth, sometimes through exploratory hands-on approaches to material development and sometimes through industrial and commercial ones. His nuanced term "correspondence" explains the co-constitution of different worlds, human and material, to which he assigns individuality and activeness in mutual co-responses to effects. He honours the entanglement of our "lines of life" with materials in a "meshwork" that is governed by correspondence rather than hylomorphic form-giving (Ingold 2012, 432), and notes Barad's call to allow "matter its due as an active participant in the world's becoming, in its ongoing 'intraactivity"” (2003, 803).

Callon, Méadel and Rabaharisoa's ideas on how goods are qualified in the economies of markets, introduced above, are particularly useful for elaborating on processes unfolding around materiality:

A product, $[\ldots]$ is an economic good seen from the point of view of its production, circulation and consumption. The concept (producere: to bring forward) shows that it consists of a sequence of actions, a series of operations that transform it, move it and cause it to change hands, to cross a series of metamorphoses that end up putting it 
into a form judged useful by an economic agent who pays for it. During these transformations its characteristics change. $(2002,197)$

They note: "The product is thus a process" (Callon et al., (2002: 197) and emphasise what we are calling the 'processuality' of materials, which the instrumental foci of scientistic approaches tend to overlook. The sense of 'processual' we intend is distinct from that found in other uses of the word, most notably with a positivistic slant in post-World War II archaeology. We do not intend our processual approach to materials to result in 'positive knowledge.' Neither are we concerned to generalize from observations of the construction of particular materials to universal social processes that affect the unfolding of all materials (Shanks and Hodder, 1995). Nor are we proposing that materials come to be through a process of 'social construction,' even stressing the human element implied by 'social,' but propose a decisive shift of view towards the ontology of materials. We use 'processuality' to encompass the contingency of agents and their ever changing dynamism and propose that design should attend to the processuality of materials, and consequently their materiality by acknowledging their multiple ontologies.

This conceptualization has far-reaching implications on how to understand the processes unfolding around materials. A 'processual' view confirms that rather than materials being stable entities that can simply be 'specified,' their meanings and effects continually shift through interactions between the physical and human worlds. This view is positive in terms of the designer's agency, confirming their role in making and manipulating material meanings as part of this process, as well as being affected by it. Our proposition is also in contrast to a view of designers as passive receivers of the meanings that users might associate with particular materials, and to the idea that designers assign meanings to materials. Reductive approaches to

Commented [LM9]: Just a comment - Frederick Kiesler proposed and published a precisely equivalent idea around 1938 in his Laboratory for Design Correlation at Columbia University. I don't know that you want to go back and reference this work, but his diagrams that depict exactly what you are talking about. It might be important for a further historical framing of your own argument. I can give you sources (mostly from my own research and several of his essays) if you are interested. The notion of material processuality, as you are defining it, has significant preWWII historical antecedents which should probably be mentioned (at least in passing) here. It's an "old" idea that is only now getting the new attention it deserves. 
understanding this process, which seek to use relatively crude interpretations of cultural categories to fix materials' meanings, down-play designers' position in an environment that contains multiple dynamics. While public opinion likes to think of them as the creative brains, out of which ideas somehow flourish spontaneously, the design process is bounded by its environment, production technicalities, the availability of materials, et cetera, and designers are but one of the agents with which things, and materials, interact in their becoming. Adopting the logic that Callon et al. develop (2002, 199), designers' input is very much part of the process of "qualification" of materials.

\section{New Smart Materials in Design - new material ontology}

In this section, we examine studies particularly on 'new materials,' which have fascinated designers as opportunities to widen the scope of their practice and research. We are talking about materials that are, literally, alive: fungus put into a chair-shaped mold, grows and lives as a chair. These materials are smart: a glove using a soft, flexible, non-Newtonian material, becomes hard and strong when hit by a hammer. They can take on human responsibilities regarding our duties to protect nature. On the one hand these materials are exciting for designers, both as innovations and as new territory to exploit, but also as examples of designers experimenting with new materials and producing exciting results such as the Mycelium chair, ${ }^{4}$ or Scherer's root fabrics, ${ }^{5}$ making designers more involved in the production of materials themselves. On the other hand, these materials are literally in the making, and in their obvious invention phase (Bijker and Pinch, 1984). However, as we will show, a scientistic approach drags along the same 'semiological' framing, and its reductive methods limit the ways we can engage with these emergent and dynamic materials. 
Intrigued by this invention phase and attending to the criticism we have laid out in the previous section that aligns with Tonuk's (2016) criticism that design takes materials as given, some recent design research on new materials claims that they are not taking materials as finished, rather they are attending to their 'unfinishedness' or 'becoming.' However, their emphasis on unfinishedness or becoming does not lead them to take into account interactions among various elements, material and immaterial, but rather the meaning of these concepts are reduced to straightforward material development - where materials are finished and find their place by designers' material development process. One such piece of work on electroactive materials loads the job of finishing materials onto designers, and even design students:

...our investigations focus specifically on the material making of the design students

$[\ldots]$ by triangulating data $[\ldots]$ we reconstructed how each final electroluminescent sample has come into being. These served as input for the analysis of the design variables/phenomena at stake and their relations to the actions and qualities evoked by the created samples. [our emphasis] (Barati et al. 2018, 4)

Here, the authors' take on "making" is also limited to the studio and to physical making, in the sense that materials are modified for certain properties and surface finishes in ways that will help designers elicit desired reactions to the designed object/material. Another work on myceliumbased composites assigns design the task of "bring[ing] forward the unique qualities of the material" (Karana et al, 2018). Although, claiming to attend to a process of 'becoming' in Ingold's sense (Barati et al, 2018) this material determinism focuses only on design's contribution to the physical re-arrangement of matter to elicit certain reactions. It ignores many elements that are actually in play in the unfolding of materials in the world, for instance the social and cultural making both during and after designing. It is clear that subtly inflected 
cultural categories, bound up with cultural principles that have social consequences, have clear effects on judgements and distinctions applied to materials, and designs, and this is evident even in this work (Karana and Hekkert, 2010a: 45). However, these attempts to attend to the cultural dimension of the 'making' of materials reduce the categories relevant to the materialization of cultural forms is to the 'cultural aspects' of large population groups (Asian/ European). This reductive approach means the operative cultural categories and principles that may affect engagement with the material world remain unexplored, introduced only in terms of unwieldy categories such as nationality or gender.

When the agentic capacity of materials is considered in this body of work, it is also dealt with somewhat literally. For instance, Barati et al. (2018) consider smart materials' physical reactions to various conditions, taking this as activeness and invoking a partial interpretation of the idea of performativity. They consider the ways in which materials perform in what are, in effect, experimental conditions, though in a design studio rather than in a laboratory. However, the idea of performativity in STS thinking takes the notion of performance decisively beyond physical change framed as the performance of a material, to encompass all the social, as well as material factors contingent on a particular enactment. This necessarily extends beyond the lab or the studio to, in simpler terms, the social performance. While in its use of these terms Barati et al.'s $(2018,2)$ work acknowledges process to the extent that it takes the materials in question to be in a process of performative characterisation, by bracketing the social/cultural dimensions of such process they deny the full original sense of the terms they use, given the fundamental importance of these dimensions to STS thinking. Ferreira and Scaraboto (2016), on the other hand, reveal the ways in which identity groups are configured around certain shoe brands and these act back on next generation shoe models. This agency of materials, in social as well as 
material terms supports our view of processuality, where materialization is ongoing and contingent, and does not finish with designers' act of making.

As a result,' literal take on the terms of the theory and the quantitative methods that scientistic approaches use with them are at odds, because social scientific and engineering approaches have different disciplinary origins, and their fundamental premises are in conflict. Social sciences, particularly 'new materialism' approaches, try to understand phenomena as they unfold in relation to different worlds, whereas for an engineering approach and for more scientistic approaches in design, materials apparently follow linear progressive paths dependent only on engineers and designers, and responding to designers' needs. While material culture and STS scholars go to a field without preconceived ideas of what they might find, scientistic hypotheses presume the existence of links between predefined elements. So, in one approach the problem is already defined, however the other foregrounds unfolding a phenomenon to understand what is at stake even if from a particular perspective.

So while the MDD approach certainly develops sophisticated experimental techniques, these limit the variables under consideration by pre-judging what is at stake, which suggests that experimental subjects can only 'know' materials through what researchers already know.

Consequently, it reduces 'meaning' and 'experience' to elements that can be addressed by those tools. Grappling with unknown and emergent materials, however, requires a different effort than forcing them into pre-existing categories. In one such study for example, the designer is positioned against nature. Their relationship to new natural materials are described using the category nature

(Colet 2017; Camere and Karana 2017), without inspecting the implications of this "most complex word" (Williams 1988, 223). When they are working with free categories, these

Commented [LM11]: Awkward sentence, please rephrase more clearly 
studies tend to use ones that are abstracted from social practices, thus predefining them. For example, in what they refer to as a "categorisation study" to understand emerging mycelium based materials, Karana et al $(2018,126)$ elicit categories in a laboratory context.

Reducing analysis to abstracted categorizations or a narrow semiotic order obviously limits the ways in which we can engage with new and emergent materials and those that cannot be yet known; cases in which there are no established 'rules of the game.' Recent studies of materials from a scientific perspective acknowledge that linear quantitative methods are not adequate for understanding our interactions with materials. What Wilkes and colleagues (2016) considerinconsistencies in their study of material experiences are exactly the sort of aberrant, unpredictable moments with material that allow design to get in touch with the complexity of human interactions with material enactments. However, this is only possible if design research on materials puts aside the assumption that meanings and experiences of materials are independent of the social practices

We propose a transformation in design's attention to materials that draws on a desire to “interrogate the 'whatness' of things” (Woolgar and Lezaun, 2015, 465; 2013, 333), to shift focus from cultural representation to matter, in Barad's formulation $(2003,802)$, or from epistemology to ontology in Woolgar and Lezaun's view. While there may not be a perfect fit between this STS discourse and matters of concern to design, it does nonetheless point towards possible correctives to problems that are thrown up by the currently prominent approaches to materials in design research literature. Central to this is the emphasis that STS discourse puts on (social) practice in determining specific enactments of the 'whatness' of things - made or found, 
material or product, stuff, or animal. As an example of the last of these, Law and Lien's study of salmon (2013) argues that different salmon are enacted by different scientific and fish-farming practices, a point also picked up by Woolgar and Lezaun:

Rather than the same salmon acquiring different 'meanings', what Law and Lien (2013) pose $[\ldots]$ is a sort of coexistence, an adjacency or at least co-presence of objects that are perfectly and discretely real. This in turn means that the ways in which differently enacted entities come to seem to be the same 'thing' is the upshot of active practical work. (2013: 325)

This quotation points to some ontological problems with much research on materials in design, reflected in its data gathering methods. Because it is lab and studio-based, it separates what a designer might do with a material (choosing it, processing it) and what a user might do in daily life - attaching meanings to it, or being affected by it. It brings these discrete worlds together in sets of categories to describe dimensions of emotional attachment or meaning as if this material were the 'same salmon' in both worlds. In reality such a material - and animal - is an object that is differently enacted in different worlds: change the world, change the material.

The design research literature on materials does go a little way in acknowledging this problem by invoking the role of 'context' for understanding materials, acknowledging that all that is significant about materials is not intrinsic to them, or to their affective consequences for those who encounter them, but rather, significance is contingent on time and place. This admission appears as a recognition of the need to consider materials in a "situational whole" of "material, product, context and individual" (Karana 2010c: 275). As noted above, one difficulty with this approach is that it is talking about situations rather than processes; another is that its appeal to 'context' is in conflict with the ontological emphasis developed in STS. As Woolgar 
and Lezaun $(2013,323)$ put it, this approach means "a refusal to draw on 'context' as an explanatory or descriptive tool," referring to 'objects' where here we are concerned with 'materials':

Objects do not acquire a particular meaning in, or because of, a given context; they cannot be accounted for by reference to the external circumstances of their existence. Rather, objects are brought into being, they are realized in the course of a certain practical activity, and when that happens, they crystallize, provisionally, a particular reality, they invoke the temporary action of a set of circumstances. $(2013,323-24)$ They offer a more inflected view of context, referring to the ethnomethodological tradition in sociology, suggesting that:

This position echoes the distinction [...] between 'context of action' and 'context in action' - that is, between context as an explanatory resource available exclusively to the analyst, and context as an emergent property of interaction available to its participants.' (Woolgar and Lezaun 2013, 324)

By this formula, the question for this discussion then, is what 'action' is being attended to in studies of materials in design - where it is happening and who are the agents? It is possible to see the design studio as a valid 'context in action,' where interactions with materiality bring materials into being and this seems to be what much of the work that promotes MDD points towards. But it combines this with a sense that materials are somehow complete and passive ingredients of such contexts, rather than being brought into being by and within them, while paradoxically, and at the same time, giving them a determining role.

As a way to unpick this paradox, we propose that design research on materials attend to 'processuality.' This term is rich in its implications: it suggests a contingency of agents, where 
multiple agents congeal around a reality. Consequently, it foregrounds relationality and connections between human and non-human elements in processes of materials' enactment, over abstract qualities taken at face value, or too-constrained by material properties. This view has consequences also for the designer as 'agent' in these processes of materialisation. Thinking about material processes in this way suggests that rather than being imaginative functionaries, serving instrumental ends by applying material meanings, designers fit the hybrid category that Klein identifies in her work on the history of technology. Thinking of designers as "hybrid savant technologists," $(2005,228)$ Klein foregrounds their ability to deploy various registers of knowledge at the same time as being able to be with materials through the process of their unfolding. This means designers' role in working with materials involves engaging with their emergent qualities, rather than 'specifying' them.

\section{Concluding Discussion: Consequences of Processuality in/for Design Research}

To twist William Morris' (1992) call for 'truth to materials,' it is appropriate to consider which of the approaches introduced above, or what combinations of them, provide insights that let us come closest to the 'truth of materials.' Materials are considered from different worlds, and thereby rendered into different 'ontologies' - they are present, they act and react in different worlds: worlds belonging to materials scientists, engineers, designers, and consumers. While scientistic approaches, particularly methods in accordance with the MDD approach seem to produce actionable results, 'tools and techniques' are always slaves to their contexts of use. We showed that these methods cannot engage with the emergent capacities of new materials, they cannot project into the future, and they are instead bound by what is known and knowable. 
Our criticism of this approach, to an extent, reduces to questions about its scope.

Considered through the limited frame of solving problems in design, production, or consumption, reductive empirical or narrative approaches have some value, but they are inadequate when the scope is widened to include the processes through which materials unfold. They also cannot adequately deal with emerging materials where no 'rules of the game' that yet exist that determine what semiotic roles they may play in the future, let alone the practices of which they will be a part. Nor do they properly inspect the cultural categories they might invoke. The sense of the foresight in the opening description of design should not be reduced to preparing for users' absolute decision with prefigured categories by quantifying responses in an isolated laboratory environment. This points towards worthwhile, further study with respect to materials and to conduct a deep study of the cultural categories implied by emergent materials that are finding valid enactments, and where the 'rules of the game' are still emerging.

While the processual approach that we frame here might not produce results that appear actionable, its objectives are different; looking for "modes of being and becoming" (the ontology) of materials. Having outlined a processual understanding that is objecting to the linguistic, intrinsic, temporally fixed and isolated views on which scientistic research builds its methods and tools, this article brings to attention that different methods are needed; methods that open up the cultural and social materializations and methods that accommodate the agency of materials, their liveliness, their complex relations, and their emergent capacities.

Our conceptualization also requires a different configuration of the designer's role, away from overreaching ambitions to be an active, deterministic force, and simultaneously away from accepting the role of passive chooser and match-maker of meanings and users. This requires design researchers to produce knowledge within the multiple relations that surround designers 
and designing. We propose instead, using Klein's $\underline{(2005,228)}$ term, a model for designers as "hybrid savant-technologists." She introduced the term to history of science literature to emphasize the interconnectedness of systems of science and technological/craft practices in the eighteenth century, using it to describe professionals exploring matter and its transformations. Designers are hybrid in the sense that they cross disciplinary boundaries, as well as are keepers of a practice that can preserve the material engagement of "hand and eye" (Rekret, 2018). Thus, our savant technologist designers have a good insight and engagement with science, but they are also hybrids in the sense of crossovers betweenscientistic and humanistic domains.

\section{Notes}

1. Ingold (2000) in his extensive criticism of cultural vs biological anthropology, takes up many aspects of producing knowledge from within different perspectives that are relevant for our discussion, and explains how they become relevant for questions of anthropology. Miller (2004) and Shove et al. (2007) discuss the limits of a view of objects explained only by semiotics, pointing to the implications of objects as physical entities that are used in the accomplishment of daily practices. Latour (1992), points out to the social construction of scientific facts to show how social and scientific worlds co-constitute each other.

2. Whereas natural scientists take 'material' to mean the substance of which products are made, and it is the common sense view of materials in design, social science discourse uses the term material or materiality for everything in material form, and this includes social, cultural, and individual relationships as well. 
3. Woolgar and Lezaun explain that the term "enactment" has a distinct notion from the notion of "social construction", that "describes practices in the here and now that produce ephemeral effects - effects essentially coextensive with the practices that create them" (2015: 463).

4. http://www.ericklarenbeek.com/

5. http://dianascherer.nl/

\section{References:}

Ashby, Mike., Brechet, D. Cebon, and L. Salvo. 2004. "Selection Strategies for Materials and Processes." Materials and Design 25: 51-67.

Barad, Karen. 2003. "Posthumanist Performativity: Toward an Understanding of How Matter Comes to Matter.” Journal of Women in Culture and Society 28, no. 3: 801-831.

Barati, Bahareh, Elisa Giaccardi, Elvin Karana. 2018. "The Making of Performativity in Designing [with] Smart Material Composites.” CHI 2018. Montréal, Canada.

Barry, Andrew. 2005. "Pharmaceutical Matters: The Invention of Informed Materials.” Theory, Culture \& Society 22, no. 1: 51-69.

Bennett, Jane. 2010. Vibrant Matter: A Political Ecology of Things. Durham, NC: Duke University Press.

Bensaude-Vincent, Bernadette., and Isabelle Stengers. 1996. A History of Chemistry. Cambridge, MA: Harvard University Press.

Callon, Michel, Cécile Méadel, and Vololona Rabeharisoa. 2002. “The Economy of Qualities.”

Economy and Society 31, no: 2: 194-217. 
Camere, Serena, and Elvin Karana. 2017. “Growing Materials for Product Design.” EKSIG2017: $101-115$.

Collet, Carole. 2017. “'Grow-Made’ Textiles.” EKSIG2017: 24-37.

Dant, Tim. 2008. “The Pragmatics of Material Interaction.” Journal of Consumer Culture 8, no. 1: $11-33$.

Drazin, Adam. 2015. “To Live in a Materials World.” In Social Life of Materials: Studies in Material and Society, edited by Drazin Adam, and Susanne Küchler, 3-28. London, New York: Bloomsbury.

Ehn, Pelle, and Morten Kyng. 1992. "Cardboard Computers: Mocking it up, or Hands on the Future.” In Design at Work: Co-operative Design of Computer Systems, edited by Joan Greenbaum and Morten Kyng, 169-196. New Jersey: L. Earlbaum Associates Inc.

Ferreira, Marcia, and Daiane Scaraboto .2016. “’My Plastic Dreams’: Towards an Extended Understanding of Materiality and the Shaping of Consumer Identities.” Journal of Business Research 69: 191-207.

Fisher, Tom. 2004. "What We Touch, Touches Us: Materials, Affects, And Affordances." Design Issues 20, no: 4: 20-31.

Fisher, Tom, and Hilde Nordli. 2009. "Emotions as Discourse - Intimations of a Socio-Cultural Approach in a Reductive Method.” In Design and Emotion Moves, edited by. Desmet, Pieter M.A, van Erp Jeroen, and MariAnne Karlsson, 126-140. Cambridge: Cambridge Scholars Publishing.

Fisher, Tom. 2015. “Fashioning Plastic.” In The Social Life of Materials: Studies in Materials and Society edited by Drazin, Adam, and Susanne Küchler, 119-137. London: Bloomsbury. 
Gabrys, Jennifer. 2013. "Plastic and the Work of the Biodegradable." In Accumulation: The

Material Politics of Plastic, edited by Gabrys, Jennifer, Gay Hawkins, and Mike Michael, 208-228. London: Routledge.

Gibson, James Jerome. 1977. "The Theory of Affordances.” In Perceiving, Acting and Knowing; Towards an Ecological Psychology, edited by Shaw, Robert, and John Bransford, 67-82. London: John Wiley.

Hawkins, Gay. 2013. "Made to Be Wasted: PET and Topologies of Disposability.” In Accumulation: The Material Politics of Plastic, edited by Gabrys, Jennifer, Gay Hawkins, and Mike Michael, 49-67. London: Routledge.

Ingold, Tim. 2000. Perception of the Environment: Essays on Livelihood, Dwelling and Skill, London: Taylor and Francis.

Ingold, Tim .2007. "Materials Against Materiality.” Archaeological Dialogues 14, no. 1: 1-16.

Ingold, Tim. 2012. "Towards and Ecology of the Materials." Annual Review of Anthropology 41, $427-442$.

Karana, Elvin, Paul Hekkert, and Prabhu Kandachar. 2008. "Material Considerations in Product Design: A Survey On Crucial Material Aspects Used by Product Designers.” Materials \& Design 29, no. 6, 1081-1089.

Karana, Elvin. 2009. “Meanings of Materials.” PhD diss., Delft University of Technology.

Karana, Elvin, Paul Hekkert, and Prabhu Kandachar. 2009. "Meanings of Materials through Sensorial Properties and Manufacturing Processes.” Materials and Design 30, no. 7: 2778-84.

Karana, Elvin, and Hekkert, Paul. 2010a. "User- Material-Product Interrelationships in Attributing Meanings.” International Journal of Design 4, no. 3: 43-52. 
Karana, Elvin, Paul Hekkert, and Prabhu Kandachar. 2010b. "A Tool for Meaning Driven Materials Selection.” Materials \& Design 31, no. 6: 2932-2941.

Karana, Elvin. 2010c. "How Do Materials Obtain Their Meanings?” Journal of the Faculty of Architecture 27, no. 2: 271-285.

Karana, Elvin, Owain Pedgeley and Valentina Rognoli. 2015a. “On Materials Experience.” Design Issues, 31, no. 3: 16-27.

Karana, Elvin, Bahareh Barati, Valentina Rognoli, and Anouk Zeeuw van der Laan. 2015b. "Material Driven Design (MDD): A Method to Design for Material Experiences." International Journal of Design 9, no. 2: 35-54.

Karana Elvin, Davine Blauwhoff, Erik-Jan Hultink, and Serena Camere. 2018. "When the Material Grows: A Case Study On Mycelium-Based Materials.” International Journal of Design 12, no. 2: 119-136.

Klein, Ursula. 2005. "Technoscience Avant la Lettre." Perspectives on Science 13, no. 2: 226266.

Latour, Bruno. 1991. “Technology Is Society Made Durable.” In A Sociology of Monsters. Essays on Power, Technology and Domination, edited by Law, John, 103-131. London: Routledge.

Latour, Bruno. 1992. "Where Are the Missing Masses? The Sociology of a Few Mundane Artifacts.” In Shaping Technology/Building Society: Studies in Sociotechnical Change, edited by Bijker, Wiebe E., and John Law, 225-258. Cambridge, Mass.: MIT Press. Latour, Bruno. 2007. Reassembling the Social. Oxford: Oxford University Press.

Law, John, and Marianne Lien. 2013. Slippery: Field Notes in Empirical Ontology. Social Studies of Science 43, no. 3: 363-378. 
Miller, Daniel, ed. 2005. Materiality. Durham, NC: Duke University Press.

Miller, Daniel. 2007. “Stone Age or Plastic Age?” Archaeological Dialogues 14, no. 1: 23-27.

Misa, Thomas. 1992. "Controversy and Closure in Technological Change: Constructing 'Steel'." In Shaping Technology/Building Society: Studies in Sociotechnical Change, edited by Bijker, Wiebe E., and John Law, 109-139. Cambridge, MA: MIT Press.

Molotch, Harvey. 2005. Where Stuff Comes from: How Toasters, Toilets, Cars, Computers and Many Other Things Come to Be as They Are. London: Routledge.

Morris, William. 1992. Hopes and Fears for Art: Lectures on Art and Industry, The Collected Works of William Morris with an Introduction by his Daughter May Morris, Vol XXII, London: Routledge/ Thoennes Press (Facsimile of the 1914 Longman Green edition).

Pinch, Trevor and Wiebe Bijker. 1984. "The Social Construction of Facts and Artefacts: Or How the Sociology of Science and the Sociology of Technology Might Benefit Each Other. Social Studies of Science 14, no. 3: 399-441.

Ramalhete, Pedro Miguel Barata de Sousa, Ana Maria de Oliveira e Rocha Senos, and Carlos Alberto Ferreira Aguiar. 2010. "Digital Tools for Material Selection in Product Design.” Materials \& Design 31, no. 5: 2275-2287.

Reckwitz, Andreas. 2002. “Toward a Theory of Social Practices: A Development in Culturalist Theorizing." European Journal of Social Theory 5(2): 243-263.

Rekret, Paul .2018. “The Head, The Hand and Matter: The New Materialisms and the Politics of Knowledge." Theory, Culture and Society 35, no. 7-8: 49-72.

Shanks, Michael, and Ian Hodder. 1995. "Processual, Postprocessual, and Interpretive Archaeologies.” In Interpreting Archaeology: Finding Meaning in the Past, edited by Ian 
Hodder, Michael Shanks, Alexandra Alexandri, Victor Buchli, John Carman, Jonathan Last, and Gavin Lucas, 3-29. London: Routledge.

Shove, Elizabeth, Matthew Watson, Martin Hand, and Jack Ingram. 2007. The Design of Everyday Life. Oxford: Berg Publishers.

Tonuk, Damla. 2016. "Making Materials: The Case of Elaborating Qualities of Bioplastics.” Design Issues 32, no. 4: 64-75.

Tonuk, Damla. 2018. "Materials as Temporally Specific Phenomena: Specialization and Compromise in Bioplastics Production.” Journal of Material Culture 23, no. 1: 114-130.

Williams, Raymond. 1988. Keywords: A Vocabulary of Culture and Society. London: Fourth Estate.

Woolgar, Steve and Javier Lezaun. 2013. "The Wrong Bin Bag: A Turn to Ontology in Science and Technology Studies?" Social Studies of Science 43, no. 3, 321 -340.

Woolgar, Steve and Javier Lezaun. 2015. "Missing the (Question) Mark? What is a Turn to Ontology?" Social Studies of Science 45, no 3: 462 -467. 